\title{
Preparation and characterization of polyaniline-silica composite material
}

\author{
U. S. Akhtar, ${ }^{a, b}$ M. S. Mirana , M. A. B. H. Susan, ${ }^{a}$ M. Y. A. Mollaha and M. M. Rahmana* \\ ${ }^{a}$ Department of Chemistry, University of Dhaka, Dhaka 1000, Bangladesh and \\ ${ }^{b}$ Chemical Research Division, BCSIR Laboratories, Chittagong, Bangladesh
}

\begin{abstract}
Polyaniline-silica (PAni-silica) composite material with $40 \%$ silica was prepared by polymerization of aniline in a medium consisting of colloidal silica, freshly prepared by hydrolysis of sodium silicate at room temperature at $\mathrm{pH} 6.5$. The physico-chemical properties of both PAni and the composite material, PAni-silica were studied by FT-IR and transmission electron microscopy and measurements of BrunauerEmmett-Teller (BET) isotherms. PAni-silica composites showed inhomogeneous pore distribution, although PAni has no significant pores. Average pore size of PAni-silica was 280 and $175 \AA$ during adsorption and desorption of nitrogen, respectively. The interactions of PAnisilica composite and PAni with saturated hydrocarbons were investigated by inverse gas chromatography. The composite material was found to be efficient for separation of a mixture of hydrocarbons, in the range of $\mathrm{C}_{5}-\mathrm{C}_{9}$, owing to large BET surface area. Enthalpy of adsorption of the individual hydrocarbons was evaluated from an analysis of the retention time and the flow rate of the carrier gas. For PAni, the enthalpy of adsorption was very low; however, the value for the composite material was found to be comparable to the enthalpy of evaporation of the individual hydrocarbons.
\end{abstract}

Key words: Polyaniline-silica composite, Enthalphy of adsorption, BET surface area, Inverse gas chromatography

\section{Introduction}

Polyaniline (PAni) is one of the most technologically important conducting materials of the modern age. It exhibits unusual chemical, electrical and optical phenomenon, both in insulating and conducting forms, which offers PAni the potential for use in diverse applications such as, in energy storage, electronics, photovoltaic devices, displays, and sensors. In fact, this promising material has drawn considerable interests since more than a century back (Ghamdi and Saigh, 2002).

Recent focus however, has been on nanocomposites based on PAni due to several intriguing properties from the mutual influence of the individual constituents (Erokhin et al. 2008). PAni based nanocomposites so far reported involve different constituents such as, inorganic nanoparticles (Schnitzler et al. 2003) and metals (Sivakumar and Gedanken, 2005), and also different forms such as, nanosheets (Kim et al. 2002), nanotubes (Zengin et al. 2002), nanobelts, and nanorods (Dutta et al. 2007). However, PAni composite materials based on oxides are still scarce in the literature. By virtue of the poor solubility and impossibility of melting, PAni is assigned to the category of "nonreprocessible" which consid- erably impedes the study of thermodynamic properties of PAni and its composite materials.

Inverse gas chromatography (IGC) appears to be good choice for the characterization of PAni since all small molecules have measurable solubility in the solid organic polymer. IGC has been receiving an upsurge of interest (Schultz et al. 1987; Jagiello et al. 1992) since it is a very versatile technique that can provide detailed thermodynamic information on both the surface and bulk properties of materials over a wide temperature range. The term 'inverse' means that the stationary phase of the chromatographic column is of interest, in contrast to conventional gas chromatography. IGC has been applied successfully for the characterization of polymers (Donnet et al. 1992; Osmont et al. 1989), clay materials (Tiburcio et al. 1991; Lara et al. 1991), zeolites (Ligner et al. 1989), carbon fibres (Chehimi et al. 1997; Carrot et al. 1984), graphite (Hradil et al. 1984), glass (Roshchina et al. 2001; Meyer, 1980) and various other organic and mineral fillers (Klahre et al. 2004). It has also been demonstrated to be suitable for the characterization of microporous (Dorris et al. 1980; Isaacson and Sawhney, 1983), macroporous 
(Ulrich and Stone, 1989), and lamellar materials (Susarla et al. 1992).

In this study, we aimed at preparing PAni-silica composites and characterizing the surface and thermodynamic properties. We prepared PAni-silica composite materials by polymerization of aniline and characterized using a wide range of experimental techniques including elemental analysis for silica content, molecular characterization by FT-IR, and morphological studies by TEM, surface area determination by BET method and surface properties including heat of adsorption and surface free energy by IGC. The ultimate goal however, has been to recognize the potential of the composite material for practical applications.

\section{Materials and Methods}

\section{Reagents}

All chemicals, aniline, $\mathrm{C}_{6} \mathrm{H}_{5}-\mathrm{NH}_{2}$ (Merck), ammonium peroxydisulfate, $\left(\mathrm{NH}_{4}\right)_{2} \mathrm{~S}_{2} \mathrm{O}_{8}$ (Merck), sodium silicate, $\mathrm{Na}_{2} \mathrm{SiO}_{3}$ (Loba Chemie), sulphuric acid, $\mathrm{H}_{2} \mathrm{SO}_{4}$, sodium carbonate, $\mathrm{Na}_{2} \mathrm{CO}_{3}$, and hydrochloric acid, $\mathrm{HCl}$ were of analytical grades and were used as received. Aniline, ammonium peroxydisulphate and sodium silicate were used as monomer, oxidant and dopant, respectively. Puric-S grade deionized water ( $R=2 \mathrm{M} \Omega \mathrm{cm}$; Organo Co., Tokyo) prepared from distilled water was used to prepare solutions.

\section{Preparation of PAni-silica}

$100 \mathrm{~mL}$ of $0.25 \mathrm{M}$ aqueous silicate solution was taken in a $1 \mathrm{~L}$ beaker and the $\mathrm{pH}$ of this solution was adjusted to 6.5 by

$$
\begin{aligned}
& \mathrm{Na}_{2} \mathrm{SiO}_{3}(\mathrm{aq})+2 \mathrm{HCl}(\mathrm{aq}) \rightarrow \mathrm{SiO}_{2}(\mathrm{~s})+2 \mathrm{Na}^{+}(\mathrm{aq})+2 \mathrm{Cl}^{-}(\mathrm{aq}) \\
& +\mathrm{H}_{2} \mathrm{O}(\mathrm{l})
\end{aligned}
$$

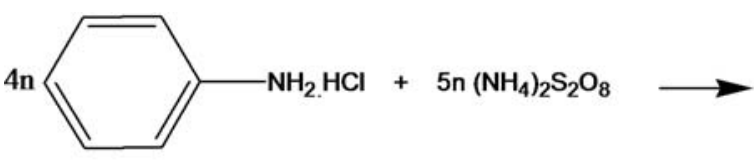

adding $2 \mathrm{M} \mathrm{HCl}$ acid. $100 \mathrm{~mL}$ of $1.25 \mathrm{M}\left(\mathrm{NH}_{4}\right)_{2} \mathrm{~S}_{2} \mathrm{O}_{8}$ solution was then added to the colloidal silica solution with constant stirring by using a magnetic stirrer. $100 \mathrm{~mL}$ of $1.0 \mathrm{M}$ solution of aniline in dil. $\mathrm{HCl}$ was then added to it. To minimize the presence of residual aniline and to obtain the best yield of PAni, the stoichiometric ratio of peroxydisulfate /aniline was maintained as 1.25 . The reaction mixture turned black within $5 \mathrm{~min}$, but vigorous stirring was continued for half an hour and was left overnight to ensure completion of the reaction.

The reaction mixture was then filtered. The resulting black sediment was redispersed in double distilled water and stirred well. The filtration-redispersion cycle was repeated several times in order to completely remove free silica particles and soluble by-products from the synthesized PAni-silica composite. The product was dried at $90-100^{\circ} \mathrm{C}$ in an oven. PAni-silica composite thus prepared was stored in screw-cap vials for analysis.

The reactions involved can be shown in Scheme 1 .

\section{Characterization of PAni-Silica Composite Materials}

\section{Analysis for Silica Content}

PAni-silica was analyzed for their silica content by removing the polymer from the composite (Vogel, 1978). Definite amount of finely powdered dry sample was weighed accurately into a platinum crucible and anhydrous sodium carbonate was added to it. The solids were mixed thoroughly by stirring with a round glass rod. The mixture was made with slight excess sodium carbonate and the crucible was covered. The mixture was heated gradually until a melt was obtained; the cover of the crucible was lifted occasionally to examine the contents. The temperature of the oven was

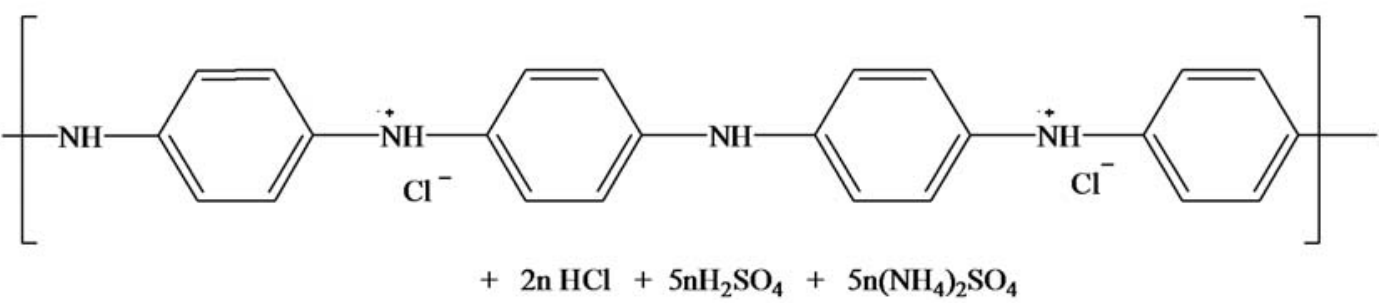

Scheme 1: Chemical reactions in PAni-silica composites. 
maintained constant for about $30 \mathrm{~min}$. The crucible with lid was cooled and placed in a porcelain basin and left overnight. About $25 \mathrm{~mL}$ of conc. $\mathrm{HCl}$ acid was added very slowly by means of a pipette into the crucible. The mixture was warmed on a steam bath until the evolution of $\mathrm{CO}_{2}$ ceased. The lid of the platinum crucible was removed, rinsed and the contents of the dish were evaporated to dryness on the steam bath. The lumps thus obtained were crushed with a glass rod. The residue was heated for an hour at $100-110^{\circ} \mathrm{C}$ to dehydrate silica.

To determine the exact silica content the grounded lumps was moistened with $1 \mathrm{~mL}$ water and 2 or 3 drops of conc. $\mathrm{H}_{2} \mathrm{SO}_{4}$ acid and about $5 \mathrm{~mL}$ of the pure $\mathrm{HCl}$ acid. The crucible was placed in an air bath and $\mathrm{HCl}$ acid was evaporated in a fume cupboard with a small flame until the acid was completely expelled; the liquid was avoided to undergo boiling. The temperature was then increased to evaporate $\mathrm{H}_{2} \mathrm{SO}_{4}$ acid and then it was cooled in a desiccator and weighed. The sample was re-heated until a constant weight could be reached.

\section{Molecular Characterization by FT-IR}

PAni and PAni-silica were analyzed by FT-IR spectrometer (Shimadzu FT-IR IR-Prestige-21) for molecular characterization. The FT-IR spectra of the samples were recorded in the region of 4000-500 $\mathrm{cm}^{-1}$ with $2 \mathrm{~cm}^{-1}$ resolution.

\section{Morphological Studies by TEM}

Transmission electron microscopic (TEM) measurements were conducted using a JEOL JEM-2011 electron microscope equipped with a charge-couple device (CCD) camera (Gatan Inc.). The accelerating voltage used was $200 \mathrm{kV}$. The TEM images were recorded at different magnifications which were calibrated using the lattice images of asbestos crystals.

\section{Determination of Surface Area by BET method}

All the samples were characterized by nitrogen adsorption/desorption isotherms at $77 \mathrm{~K}$ measured using a Micromeritics Gemini ASAP 2000 system. The pore size data were analysed by the thermodynamic based BarrettJoyner-Halenda (BJH) method using the desorption branch of the isotherm and surface areas were measured using the Brunauer-Emmett-Teller (BET) method.

\section{Chromatographic Measurements}

A mixture ( $1 \mathrm{~mL}$ each) of five alkanes, viz, pentane, hexane, heptane, octane and nonane were used as probes with helium as the carrier gas. The flow rate was maintained at $23 \mathrm{~mL}$ $\min ^{-1}$ as measured by a soap-bubble flow meter. The injection and detection temperatures were maintained at $180{ }^{\circ} \mathrm{C}$ each. The column was conditioned at $120^{\circ} \mathrm{C}$ under a stream of nitrogen gas for several hours prior to chromatographic measurements. $0.5 \mu \mathrm{L}$ probe was injected manually by a Hamilton gas-tight micro-syringe. Retention time was recorded graphically at maximum sensitivity.

\section{Results and Discussion}

PAni-silica composite was prepared by polymerization of aniline in presence of freshly prepared colloidal silica. The rate of hydrolysis of sodium silicate is very much dependent on the $\mathrm{pH}$ of the medium. Therefore, optimum conditions were fixed for the preparation of colloidal silica by the hydrolysis of sodium silicate. It was found that at a $\mathrm{pH}$ of 6.5 , colloidal silica was produced in a reaction time of about $5 \mathrm{~min}$. The analysis of silica content shows that the PAnisilca composite prepared has the silica content identical to the feed ratio of silica (40\%).

\section{Molecular Characterization by FT-IR}

The FT-IR spectrum of a compound is characteristic of the molecule; however, certain groups of atoms present in the molecule may give rise to bands at or near the frequency regardless of the structure of the rest of the molecule. We have analyzed the FT-IR spectra to obtain qualitative information of the synthesized PAni-silica and PAni. The observed bands assigned for different functional groups (Sharma et al. 1993; Pavia et al. 1979) present in the PAnisilica composite material are summarized in Table I. The reference band positions are also shown.

\section{Pore Volume Distribution of Nitrogen Adsorption- Desorption Histogram}

Fig. 1(a) shows the adsorption isotherm of nitrogen at liquid nitrogen temperature on PAni-silica composite. It should be noted that PAni-silica underwent evaporation while heating during pre-treatment; therefore, it was processed without application of heat. The desorption of nitrogen at this temperature shows a hysterics branch. This indicates the presence of pores in the sample. The desorption branch was 
Table I: Assignments of band positions in the FT-IR spectra of a PAni-silica composite

\begin{tabular}{|c|c|c|c|}
\hline $\begin{array}{l}\text { Functional } \\
\text { groups }\end{array}$ & $\begin{array}{l}\text { Standard absorption } \\
\text { band range }\left(\mathrm{cm}^{-1}\right)\end{array}$ & $\begin{array}{l}\text { Observed absorption } \\
\text { bands }\left(\mathrm{cm}^{-1}\right)\end{array}$ & Probable assignments \\
\hline $\mathrm{O}-\mathrm{H}$ & $3650-3200$ & $3500-3400$ & O-H stretching vibration; Water may be present \\
\hline $\mathrm{N}-\mathrm{H}$ & $3500-3100$ & $3300-3200$ & Aromatic secondary amine may be present \\
\hline $\mathrm{C}=\mathrm{C}$ & $1600-1450$ & $1525-1475$ & $\mathrm{C}=\mathrm{C}$ bond stretching in aromatic double bond \\
\hline $\mathrm{C}-\mathrm{N}$ & $1350-1250$ & $1300-1250$ & $\mathrm{C}-\mathrm{N}$ stretching in aromatic amine \\
\hline $\mathrm{C}=\mathrm{N}$ & $1700-1600$ & $1700-1600$ & $\mathrm{C}=\mathrm{N}$ stretching in imine \\
\hline \multirow[t]{2}{*}{$\mathrm{C}-\mathrm{H}$} & $3000-2800$ & $3000-2850$ & $\mathrm{C}-\mathrm{H}$ stretching and $\mathrm{C}-\mathrm{H}$ bending \\
\hline & $900-690$ & $850-800$ & unsubstituted benzene \\
\hline Si-O & $1111-801$ & $1100-1050$ & Presence of silica \\
\hline
\end{tabular}

analysed according to BJH method. Fig. 1(b) shows the pore size distribution. The distribution is rather inhomogeneous and particles with pore diameter of about $30 \mathrm{~nm}$ appear to be most abundant. Average pore size of PAni-silica was 280 and $175 \AA$ during adsorption and desorption of nitrogen, respectively. The BET surface area calculated by pore size shows that formation of PAni-silica composite increased surface area from 41.5 to $78.3 \mathrm{~m}^{2} \mathrm{~g}^{-1}$.

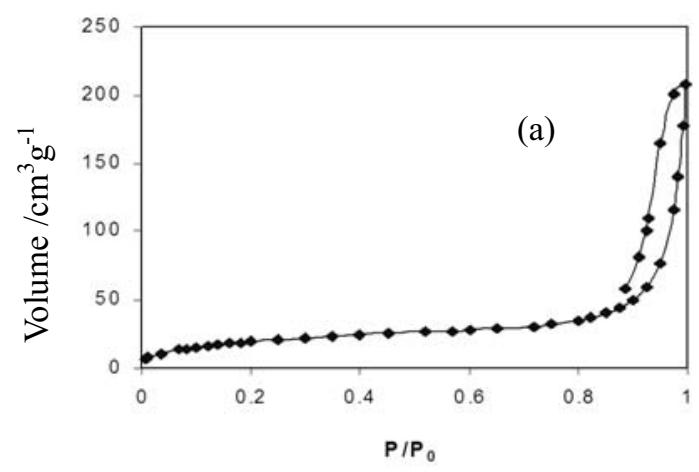

PAni. This indicates, PAni has no significant pores. Fig. 2 (b) shows pore size distributions for PAni.

Morphological Studies by TEM

Strip morphology was found in PAni-silica composite and no pore could be identified in the TEM image of pure PAni (Fig. 3a). A portion of the TEM image is too dark in PAni-silica

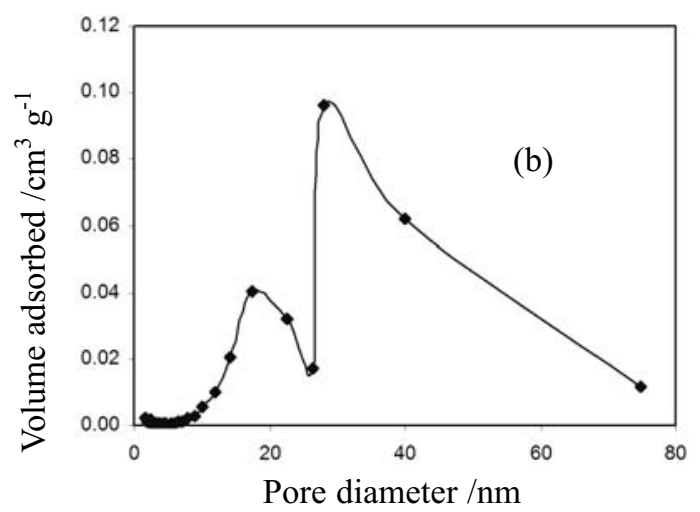

Fig. 1: (a) $\mathrm{N}_{2}$ adsorption-desorption isotherm and (b) pore size distribution for PAni-silica composite.

Fig. 2 (a) shows the adsorption-desorption isotherm of nitrogen adsorption-desorption at liquid nitrogen temperature on

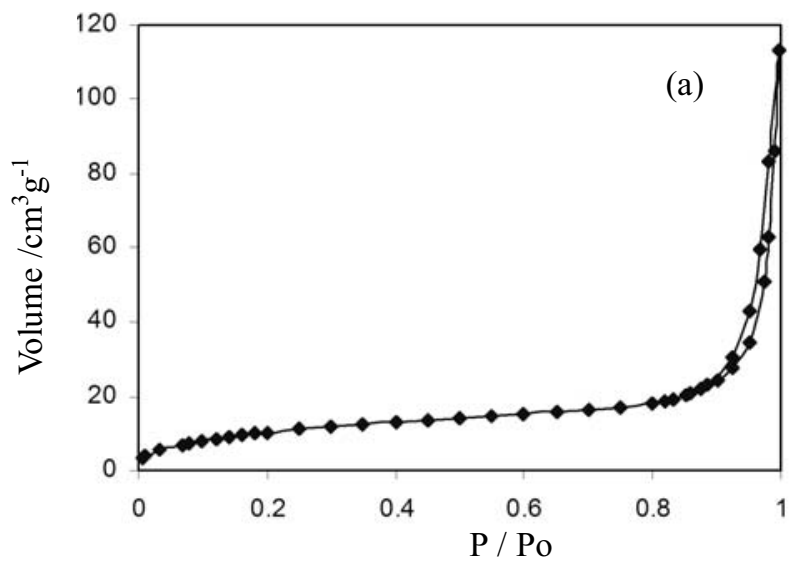

composite (Fig. 3b) indicating that the specimen sample was too thick for TEM imaging and electron could not penetrate

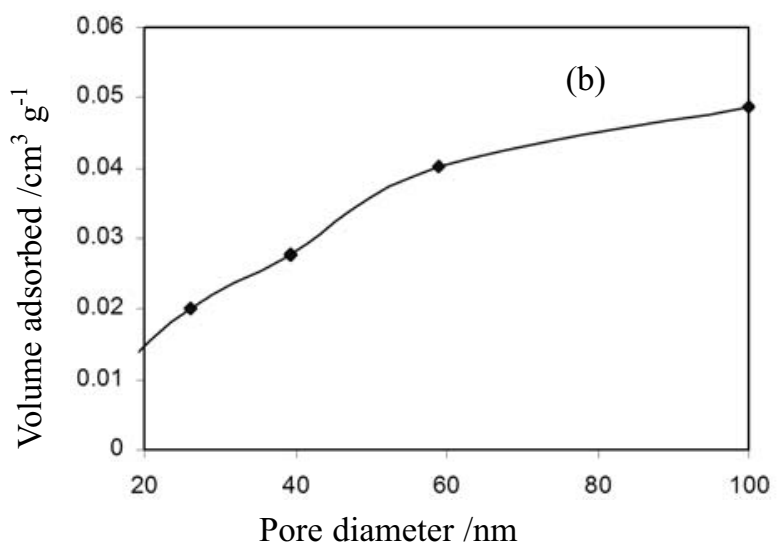

Fig. 2: (a) $\mathrm{N}_{2}$ adsorption-desorption isotherm and (b) pore size distribution for PAni. 
through that portion (mass contrast). Other part of the image (Fig. 3b) for the composite contains bubble like structure and indicates the presence of few pores. We assumed that these areas are artifacts left over from some of the prior processing of the material or contamination as this structure was not found regularly.
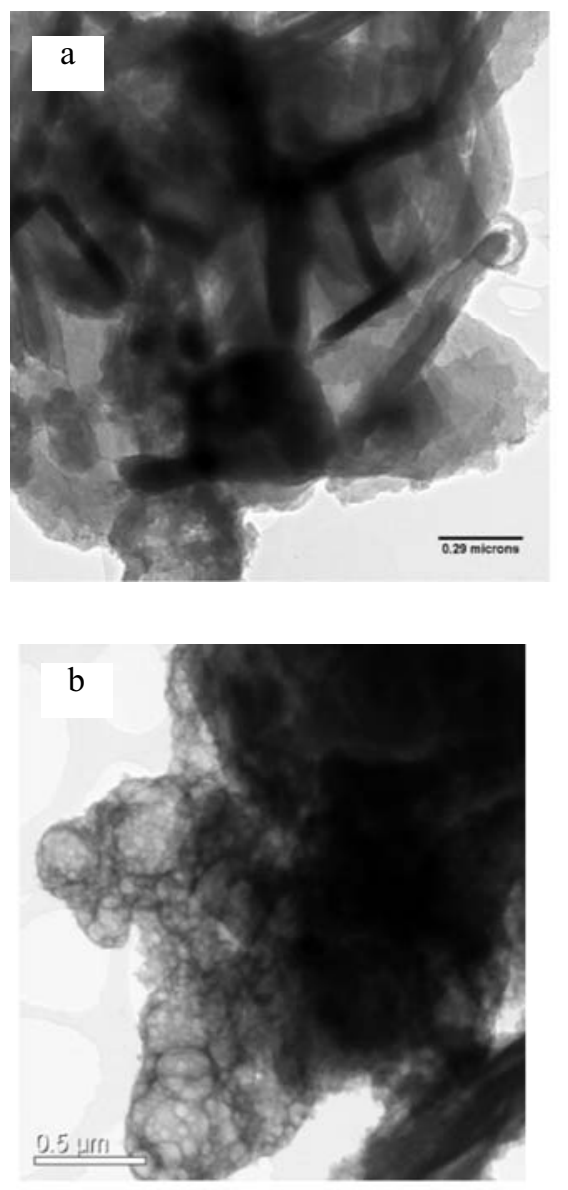

Fig. 3: TEM images of (a) PAni and (b) PAni-silica composite.

Characterization of PAni and PAni-silica Composite by IGC

PAni and PAni-silica were characterized by IGC. Very long retention time was found for hydrocarbon probes viz. pentane to nonane used in this study. Hydrocarbons were found to be separated by a column of $50 \mathrm{~cm}$ length; but retention time was very low compared to that of PAni-silica composite materials.

In IGC, probes are injected at infinite dilution and behave independently thus lateral probe-probe interactions are neg- ligible. Therefore, the retention on the solid surface is governed only on solid-probe interactions. The retention volume, $V_{N}$ is related to $t_{\mathrm{N}}$, the net retention time by

$$
V_{\mathrm{N}}=j F\left(1-\frac{P_{\mathrm{w}}}{P_{\mathrm{a}}}\right)\left(\frac{T_{\mathrm{c}}}{T_{\mathrm{a}}}\right) t_{\mathrm{N}}
$$

where $j$ is the compression factor, $F$ is the carrier gas flow rate, $P_{a}$ is the ambient pressure at $25{ }^{\circ} \mathrm{C}, T_{a}$ is the ambient temperature, $T_{c}$ is the column temperature, and $P_{w}$ is the partial pressure of water at ambient temperature. In the present experiment, $P_{a}=750.06 \mathrm{~mm} \mathrm{Hg}, T_{a}=25{ }^{\circ} \mathrm{C}$ and $P_{w}=23.8$ $\mathrm{mm} \mathrm{Hg}$ and $F=23 \mathrm{mLmin}^{-1}$ for PAni-silica and $F=31$ $\mathrm{mLmin}^{-1}$ for PAni. Retention volume $\left(V_{N}\right)$ was calculated by using eq. 1 .

The free energy of adsorption, $\Delta \mathrm{G}_{\mathrm{a}}$ is related to $V_{\mathrm{N}}$ by

$$
-\Delta G_{\mathrm{a}},=\mathrm{R} T \ln \left(V_{N}\right)+C
$$

where $R$ is the gas constant, $T$ is the column temperature and $C$ is constant. The adsorption enthalpy $\left(\Delta \mathrm{H}_{\mathrm{ads}}\right)$ can be calculated from the Gibbs-Helmholtz equation

$$
\frac{\partial\left(\frac{\Delta G_{\text {ads }}}{T}\right)}{\partial T}=-\frac{\Delta H_{\text {ads }}}{T^{2}}=-R \frac{d \ln V_{\mathrm{N}}}{d T}
$$

The variation of $\Delta \mathrm{G}_{\mathrm{a}}$ or $\left(\mathrm{RT} \ln \left(\mathrm{V}_{\mathrm{N}}\right)\right)$ with temperature allows the determination of $\Delta \mathrm{H}_{\mathrm{a}}$, the enthalpy of adsorption.

$$
-\Delta H_{\mathrm{a}}=\frac{R d\left(\ln V_{\mathrm{N}}\right)}{d\left(\frac{1}{T}\right)}
$$

The $\Delta \mathrm{H}_{\mathrm{a}}$, values were determined at $80{ }^{\circ} \mathrm{C}$ and $90{ }^{\circ} \mathrm{C}$ and are plotted as a function of number of carbons in the hydrocarbons in Fig. 4. It is worth mentioning that the $\Delta \mathrm{H}_{\mathrm{a}}$, values are negative or very low for PAni. This is indicative of physical adsorption and enthalpy of adsorption is very low compared to the enthalphy of evaporation of alkanes. Therefore adsorption of these hydrocarbon probes on PAni is less probable. On the other hand, enthalpy of adsorption of alkanes in PAni-silica composites was comparable to the enthalpy of vaporization of the alkanes. PAni-silica composite material can thus be used as good column materials for the separation of alkanes $\left(\mathrm{C}_{5}-\mathrm{C}_{9}\right)$. 


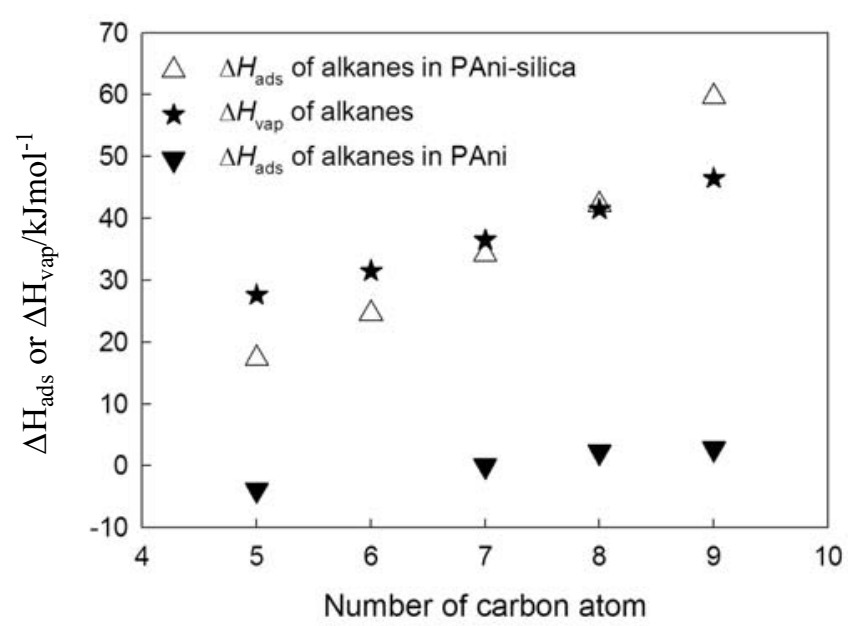

Fig. 4: Enthalpy of adsorption for $\boldsymbol{n}$-alkanes adsorbed on to PAni and PAni-silica composite.

Determination of the London component of the surface free energy

The method of Dorris and Gray (Grim, 1968) was applied to determine $\gamma_{\mathrm{s}}^{\mathrm{d}}$ using the retention data of the $n$-alkanes series. Plotting $\Delta \mathrm{G}_{\mathrm{a}}$ or $R T \ln \left(\mathrm{V}_{\mathrm{N}}\right)$ values vs. the number of carbon atoms in the alkanes results in the linear correlation (Fig. 5)

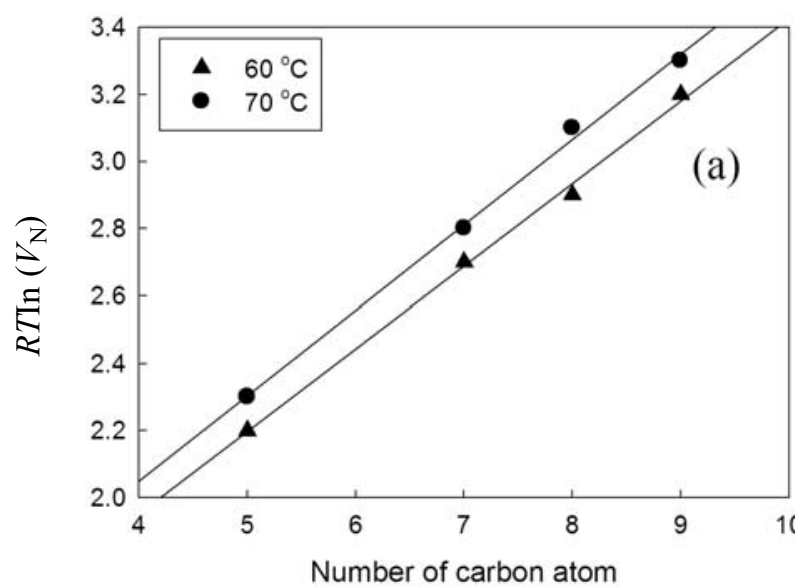

The free energy of adsorption per methylene group, $\gamma_{\mathrm{s}}^{\mathrm{d}}$ is related to the square of $\Delta \mathrm{G}_{\mathrm{a}}{ }^{\mathrm{CH}}{ }_{2}$ by

$$
\gamma_{s}^{d}=\frac{1}{4 \gamma_{\mathrm{CH}_{2}}}\left(\frac{\Delta G_{a}^{\mathrm{CH}_{2}}}{\mathrm{Na}_{\mathrm{CH}_{2}}}\right)^{2}
$$

where $N$ is Avogadro's number, $a_{\mathrm{CH}_{2}}$, the cross-sectional area of an adsorbed methylene $\left(\mathrm{CH}_{2}\right)$ is $6,(\stackrel{\mathrm{A}}{2})^{2}, \gamma_{\mathrm{CH}_{2}}$ is the surface free energy of a solid, $\gamma_{\mathrm{CH}_{2}}=36.8-0.058 \mathrm{~T}\left({ }^{\circ} \mathrm{C}\right)$ Using eq. 5, we obtained, $\gamma_{\mathrm{s}}^{\mathrm{d}}=35.5 \mathrm{mJm}^{-2}$ at $80{ }^{\circ} \mathrm{C}$ and $\gamma_{\mathrm{s}}^{\mathrm{d}}=29.9$ $\mathrm{mJm}^{-2}$ at $90{ }^{\circ} \mathrm{C}$ for PAni-silica composite. The value of $\gamma_{\mathrm{s}}^{\mathrm{d}}$ has also been evaluated as $38.5 \mathrm{mJm}^{-2}$ and $39.8 \mathrm{mJm}^{-2}$ at $60{ }^{\circ} \mathrm{C}$ and $70{ }^{\circ} \mathrm{C}$, respectively for for PAni.

\section{Conclusion}

PAni-silica composite material was synthesized by polymerizing aniline in presence of colloidal silica prepared in situ from aqueous sodium silicate solution. Incorporation of silica into the PAni matrix resulted in an increase in the surface area for PAni-silica composite. PAni-silica composites showed inhomogeneity in pore distribution; although PAni has no significant pores. Average pore size of PAni-silica

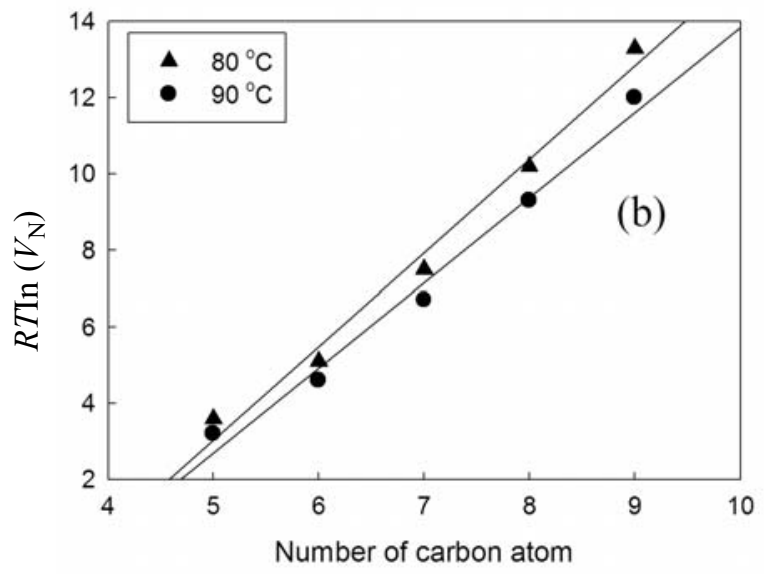

Fig. 5: $R T \ln \left(V_{N}\right)$ as a function of number of carbon atoms for $n$-alkanes adsorbed on to (a) PAni (b) PAni-silica composite at two different temperatures.

with the slope equal to $\Delta \mathrm{G}_{\mathrm{a}}{ }^{\mathrm{CH}}{ }_{2}$ at $80^{\circ} \mathrm{C}, \Delta G_{\mathrm{a}}{ }^{\mathrm{CH}}{ }_{2}=2.4$ $\mathrm{kJmol}^{-1}$ and at $90{ }^{\circ} \mathrm{C}, \Delta \mathrm{G}_{\mathrm{a}}{ }^{\mathrm{CH}}{ }_{2}=2.2 \mathrm{kJmol}^{-1}$ for PAni-silica composite and at $60{ }^{\circ} \mathrm{C}, \Delta \mathrm{G}_{\mathrm{a}}{ }^{\mathrm{CH}}{ }_{2}=2.59 \mathrm{kJmol}^{-1}$ and at $70{ }^{\circ} \mathrm{C}$ $\Delta G_{\mathrm{a}}{ }_{2}{ }_{2}=2.61 \mathrm{kJmol}^{-1}$ for PAni. was 280 and $175 \AA$ during adsorption and desorption of nitrogen, respectively. The PAni-silica composite exhibited higher surface energy and BET surface area than those for the bulk polymer. Finally, the PAni-silica composite may be used as column materials to separate linear hydrocarbons in the range $\mathrm{C}_{5}-\mathrm{C}_{9}$. Further studies are underway to correlate 
physicochemical parameters of the PAni-silica composite materials with silica content.

\section{Acknowledgement}

The authors gratefully acknowledge financial support for a sub-project (CP-231) from the Higher Education Quality Enhancement Project of the University Grants Commission of Bangladesh financed by World Bank and the Government of Bangladesh. Authors also acknowledge kind support from Instrumental Analysis Center of Yokohama National University, Japan for TEM measurements and pore size distribution experiments.

\section{References}

Carrot PJM, Roberts RA and Sing KSW (1987). Gas chromatographic study of microporous carbon. $J$. Chromatogr. A. 406: 139-144.

Chehimi MM, Abel M, Sahraui Z, Fraoua K, Lascelles S and Armes SP (1997). Time-dependent variation of the surface energy of conducting polypyrrole. J. Adhesion Adhesives 17: 1-8.

Donnet JB, Park SJ and Brendle M (1992). The effect of microwave plasma treatment on the surface energy of graphite as measured by inverse gas chromatography. Carbon 30: 263-268.

Dorris GM and Gray DG (1980). Adsorption of $n$-alkanes at zero surface coverage on cellulose paper and wood fibers. J. Coll. Interface Sci. 77: 353-362.

Dutta K, De S and De SK (2007). Optical and electrical characterization of self-assembled CdS nanorods-polyaniline composites. J. Appl. Phys. 101: 093711-16.

Dyer JR (1991). Application of absorption spectroscopy of organic compounds. Prentice-Hall, New Delhi, p 37.

Erokhin V, Ram M and Yavuz O (eds), (2008). The new frontiers of organic and composite nanotechnology. (Elsevier, London) pp 143-235.

Ghamdi AA and Saigh ZYA (2002). Surface and thermodynamic characterization of conducting polymers by inverse gas chromatography. J. Chromatogr. A. 969: 229-243.

Grim RE 1968. Clay Mineralogy. 2nd edition, McGrawHill, New York, p 47.

Hradil J and Svec F (1984). Investigation of the surface structure of polymers by chromatographic methods : VI. Determination of glass transition temperature of macroporous copolymers by gas chromatography. $J$. Chromatogr. A. 287: 67-76.

Isaacson RJ and Sawhney BI (1983). Sorption and transformation of phenols on clay surfaces. Clay Minerals 18: 253-265.

Jagiello J, Bandosz TJ and Schwarz JA (1992). Inverse gas chromatographic study of activated carbons: The effect of controlled oxidation on microstructure and surface chemical functionality. J. Coll. Interface Sci. 151: 433445 .

Kim BH, Jung JH, Hong SH, Joo J, Epstein AJ and Mizoguchi K (2002). Nanocomposite of polyanilinemontmorillonite clay. Macromoleules, 35: 1419-23.

Klahre P and Klump E (2004). Hydrotalcite as a potential sorbent for the removal of 2,4-DCP. Turk. J. Eng. Env. Sci. 28: 41-48.

Lara LSJ and Schreiber HP (1991). Specific interaction and adsorption of film-forming polymers. J. Coat. Technol 63: 81-90.

Ligner G, Vidal A, Balard H and Papier E (1989). Variation of the specific interaction capacity of heat-treated amorphous and crystalline silicas. J. Coll. Interface Sci. 134: 486-496.

Meyer EF (1980). On thermodynamics of adsorption using gas-solid chromatography. J. Chem. Edu., 57: 120-124.

Osmont E and Schrieber HP (1989). Surface characterization of glass fibres. ACS Symp. Series, 391: 230-247.

Pavia DL, Lampman GM and Kriz GS (1979). Introduction of spectroscopy. Saunder College Publishing, USA. 
Roshchina, TM Shonia NK, Kazmina AA, Gurevich KB and Fadeev AY 2001. Adsorption study of alkyl-silicas and methylsiloxy-silicas. J. Chromatogr. A 931: 119-127.

Schnitzler DC, Meruvia MS, Hummelgen IA and Zarbin AIG (2003). Preparation and characterization of novel hybrid materials formed from ( $\mathrm{Ti}, \mathrm{Sn}) \mathrm{O}_{2}$ nanoparticles and polyaniline. Chem. Mater. 15: 4658-65.

Schultz J, Lavielle L and Martein C (1987). The role of the interface in carbon fibre-epoxy composites. $J$. Adhesion Adhesives 23: 45-60.

Sharma YR (1993). Elementary organic spectroscopy. S. Chand. Company Ltd., New Delhi, India, p 80.

Sivakumar M and Gedanken AA (2005). A sonochemical method for the synthesis of polyaniline and $\mathrm{Au}$ polyaniline composites using $\mathrm{H}_{2} \mathrm{O}_{2}$ for enhancing rate and yield. Syn. Metal. 148: 301-6.
Susarla S, Bhamidimarri SMR and Bhaskar GV (1992). Competitive adsorption and desorption of a phenoxy herbicide and a chlorophenol in a volcanic soil. Proc. 47th Industrial Waste Conference 14: 151-158.

Tiburcio AC and Manson JA (1991). Acid-base interactions in filler characterization by inverse gas chromatography. J. Appl. Polym. Sci. 42: 427-438.

Ulrich HJ and Stone AT (1989). Oxidation of chlorophenols adsorbed to manganese oxide surfaces. Environ. Sci. Technol, 23: 421-428.

Vogel I (1978). A text book of quantitative inorganic analysis. 4th edn, Longman, UK, pp 580-581.

Zengin H, Zhou W, Jin J, Czerw R and Smith, Jr. DW, Echegoyen L (2002). Carbon nanotube doped polyaniline. Adv. Mater., 14: 1480-3.

Received: 25 March 2012; Revised: 07 August 2012; Accepted: 08 August 2012. 